\title{
HUBUNGAN PELAKSANAAN FUNGSI MANAJEMEN KEPALA RUANGAN DENGAN PENERAPAN PATIENT SAFETY DI RUANG PERAWATAN RSUD KOTA MAKASSAR
}

\section{Correlation Between The Implementation of Management Function of Head Nurse and Patient Safety in Treatment Ward Makassar City Hospital}

\section{La Masahuddin*1, Rini Rachmawaty2, Burhanuddin Bahar2}

1. Mahasiswa Magister Ilmu Keperawatan Fakultas Keperawatan Universitas Hasanuddin Makassar

2. Dosen Magister Ilmu Keperawatan Fakultas Keperawatan Universitas Hasanuddin Makassar

\section{Riwayat artikel}

Diajukan: 5 Agustus 2019

Diterima: 28 Maret 2020

\section{Penulis Korespondensi:}

- La Masahuddin

- Universitas Hasanuddin

Makasar

nersokha@gmail.com

\section{Kata Kunci:}

Fungsi Manajemen

Kepala ruangan, patient safety, perawat

\section{Abstrak}

Pendahuluan: Gerakan "Patient safety" atau Keselamatan Pasien telah menjadi spirit dalam pelayanan keperawatan rumah sakit di seluruh dunia, tidak hanya rumah sakit di negara maju yang menerapkan keselamatan pasien untuk menjamin mutu pelayanan kesehatan dan keperawatan, tetapi juga rumah sakit di negara berkembang, seperti Indonesia.

Tujuan: Diketahui hubungan pelaksanaan fungsi perencanaan, pengorganisasian, pengarahan dan pengendalian kepala ruangan dengan penerapan keselamatan pasien oleh perawat di RSUD Kota Makassar.

Metode : penelitian merupakan penelitian kuantitatif dengan pendekatan cross sectional. Penelitian dilaksanakan di ruang rawat inap Rumah Sakit Umum Daerah Kota Makassar terhadap 63 orang perawat pelaksana (simple random sampling). Metode pengumpulan data menggunakan kuesioner checklist dengan menyebarkan angket, pelakasanaan fungsi manajemen kepala ruang dengan penerapan patient safety menggunakan uji korelasi spearman's rho.

Hasil : Hasil penelitian menunjukkan ada hubungan yang signifikan antara fungsi manajemen kepala ruangan dengan penerapan patient safety oleh perawat di RSUD Kota Makassar dengan nilai $p=0,009$ dan nilai korelasi Spearman's rho 0,327 , pada pengorganisasian diperoleh nilai $p=0,042$ dan nilai korelasi spearman 0,257 , pada pengendalian diperoleh nilai $p=0,023$ dan nilai korelasi spearman 0,285 . Tidak ada hubungan yang signifikan antara pelaksanaan fungsi manajemen perencanaan kepala ruangan diperoleh nilai $p=0,095$ dan nilai korelasi Spearman's rho 0,212, pada fungsi pengarahan kepala ruang dengan penerapan patient safety dengan nilai $p=0,530$ dan nilai korelasi spearman 0,081.Pembahasan hasil penelitian menunjukan bahwa semakin baik pelaksanaan fungsi manajemen kepala ruangan maka semakin baik penerapan patient safety oleh perawat di RSUD Kota Makassar

Kesimpulan: Kepala ruang perlu untuk selalu meningkatkan fungsi perencanaan dan pengarahan dalam upaya membudayakan penerapan patient safety sehingga akan terciptanya kualitas keselamatan pasien yang baik di lingkungan pelayanan RSUD Kota Makassar.

\section{Abstract}

Introduction: The "Patient safety" movement has become a spirit in hospital nursing services throughout the world, not only hospitals in developed countries that implement patient safety to ensure the quality of health and nursing services, but also hospitals in developing countries, such as Indonesia. Objective: The relationship between the 
implementation of the functions of planning, organizing, directing and controlling the head of the room with the application of patient safety by nurses in Makassar City Hospital. Method: this research is a quantitative research with cross sectional approach. The study was conducted in the inpatient room of the Makassar City General Hospital of 63 nurses implementing it (simple random sampling). The method of collecting data using a checklist questionnaire by distributing questionnaires, the implementation of head room management functions with the application of patient safety using the Spearman 's rho correlation test. Results: The results showed that there was a significant relationship between the function of head room management with the application of patient safety by nurses in Makassar City Hospital with a value of $p=0.009$ and $a$ Spearman's rho correlation value of 0.327 , in organizing a value of $p=$ 0.042 and a spearman correlation value of 0.257 , at controlling for $p$ value $=0,023$ and spearman correlation value 0,285. There is no significant relationship between the implementation of the head room planning management function obtained $p$ value $=0.095$ and Spearman's correlation value rho 0.212, the head room directional function with the application of patient safety with a value of $p=0.530$ and the spearman correlation value of 0.081. Discussion : of the results showed that the more the better the implementation of the head room management function, the better the implementation of patient safety by nurses in Makassar City Hospital. Conclusion: The head of the room needs to always improve the planning and direction function in an effort to civilize the application of patient safety so that there will be a good quality of patient safety in the Makassar City Hospital service environment.

\section{PENDAHULUAN}

Rumah Sakit merupakan institusi pelayanan kesehatan bagi masyarakat yang dipengaruhi oleh perkembangan ilmu pengetahuan kesehatan, kemajuan teknologi, dan kehidupan sosial ekonomi masyarakat yang harus tetap mampu meningkatkan pelayanan yang lebih bermutu dan terjangkau oleh masyarakat agar terwujud derajat kesehatan yang setinggi-tingginya. Untuk mencapai hal tersebut diperlukan upaya peningkatan mutu pelayanan rumah sakit yang komprehensif dan integratif meliputi proses dan outcome secara obyektif, sistematik dan berlanjut memantau dan menilai mutu pelayanan terhadap pasien, sehingga pelayanan yang diberikan di rumah sakit lebih bermutu.
Pelayanan keperawatan di rumah sakit merupakan aktivitas terbesar dalam pelayanan kesehatan sehingga mencerminkan mutu pelayanan rumah sakit. Mengingat kedudukan tenaga keperawatan yang penting, maka hubungan yang baik antara manajemen rumah sakit dan tenaga keperawatan diperlukan.1

Keselamatan pasien (patient safety) menjadi isu global dan merupakan prioritas utama untuk dilaksanakan di rumah sakit. World Alliance for Patient Safety, Forward Programme WHO menyatakan bahwa keselamatan merupakan prinsip dasar dalam perawatan pasien dan merupakan komponen kritis dari manajemen mutu rumah sakit. Hal ini melahirkan paradigma baru tentang mutu pelayanan, bahwa mutu pelayanan yang baik saja tidak cukup berarti bagi pasien 
tanpa memperhatikan bagaimana derajat unsur resiko dan keselamatan pasien.2

Manajemen

merupakan pengelolaan aktivitas keperawatan oleh manajer keperawatan melalui kegiatan manajerial terhadap perawat pelaksana dalam penyelenggaraan pelayanan keperawatan kepada pasien/ keluarga/ masyarakat secara profesional. Kepala ruangan sebagai Manajer keperawatan di setiap ruang perawatan dituntut untuk merencanakan, mengorganisasikan,

mengarahkan, mengendalikan dan mengevaluasi sarana dan prasarana yang tersedia untuk dapat memberikan jaminan keamanan dan kenyamanan yang melindungi keselamatan pasien perawat dan keluarga pasien. Perawat dituntut untuk memberikan asuhan keperawatan yang seefektif dan seefisien mungkin bagi individu, keluarga dan masyarakat sesuai kode etik dan standard. praktek keperawatan. Manajemen adalah proses mengumpulkan dan mengorganisir sumber daya, saran dan prasarana dalam mencapai tujuan yang mencerminkan kedinamisan organisasi. Keselamatan pasien merupakan tujuan utama dalam memberikan asuhan keperawatan, dan pelayanan praktek keperawatan di rumah sakit. Keselamatan pasien dapat terjaga apabila dilaksanakan dengan berpedoman pada standar asuhan keperawatan dan memberikan jaminan mutu pelayanan.

Perawat sebagai petugas kesehatan yang paling banyak berinteraksi dengan pasien, memiliki resiko lebih tinggi terhadap bahaya keselamatan dibandingkan petugas kesehatan lainya. Kondisi ini menuntut perawat untuk memperhatikan keselamatan bagi dirinya, pasien dan keluarga pasien pada saat bekerja agar dapat memberikan asuhan keperawatan yang aman bagi pasien. Salah satu cara untuk melindungi keselamatan pasien adalah agar dapat mencegah terjadinya penularan penyakit dengan menggunakan alat pelindung diri (APD) pada saat memberikan asuhan keperawatan pada pasien penyakit menular. Hal ini tidak lepas dari peran manajemen keperawatan untuk menyediakan alat pelindung diri bagi perawat yang memberikan asuhan keperawatan.

Pelayanan keperawatan yang bermutu tidak sepenuhnya menjadi tanggung jawab perawat pelaksana, kepala Ruang sebagai manajer lini pelayanan terdepan mempunyai tanggung jawab terhadap aktifitas proses keperawatan dan menfasilitasi pelaksanaan keperawatan agar dapat melaksanakan praktek keperawatan sesuai standar.

Keselamatan pasien (patient safety) telah menjadi indikator penting dalam pelayanan kesehatan di rumah sakit. Keselamatan dalam pelayanan kesehatan merupakan prinsip yang paling mendasar dan bukan merupakan suatu pilihan tetapi menjadi hak setiap pasien yang telah melimpahkan kepercayaannya kepada tenaga kesehatan terutama perawat sebagai pemberi pelayanan keperawatan di rumah sakit. Pelayanan keperawatan dan kesehatan merupakan suatu proses yang sangat kompleks dan tidak selalu aman karena dipengaruhi oleh banyak faktor, sehingga memungkinkan dapat terjadi pelayanan atau hasil pelayanan yang tidak diperkirakan atau tidak diinginkan.

Pasien meninggal dunia atau cacat tetap merupakan kejadian paling berat yang mungkin terjadi akibat kesalahan dalam pemberian pelayanan keperawatan dan kesehatan oleh perawat dan petugas kesehatan yang lain di rumah sakit.

Penyakit menular adalah penyakit yang ditularkan melalui berbagai media. Penyakit jenis ini merupakan masalah kesehatan yang besar pada semua negara, karena angka kesakitan dan kematiannya yang relatif tinggi dalam waktu relatif singkat. Penyakit menular masih menjadi prioritas karena sifat menularnya yang dapat menyebabkan wabah dan menimbulkan kerugian yang cukup besar. Penyakit menular merupakan perpaduan faktor lingkungan (environment), agen penyebab penyakit (agent) dan penjamu 
(host), ketiga faktor ini merupakan segitiga epidemiologi

(epidemiological triangle). Penyakit menular (Communicable diseases) adalah penyakit infeksi yang didapat dari orang atau hewan sakit, dari benda-benda yang mengandung bibit penyakit lainnya ke manusia yang sehat.

Berdasarkan data dari KKP-RS

2008 Di Indonesia laporan insiden keselamatan pasien berdasarkan propinsi, pada tahun 2007 ditemukan Propinsi DKI Jakarta menempati urutan tertinggi yaitu $37,9 \%$ di antara delapan propinsi lainnya Jawa Tengah 15,9\%, D.I Yogyakarta 13,8\%, Jawa Timur 11,7\%, Sumatra Selatan 6,9\%, Jawa Barat 2,8\%, Bali $1,7 \%$, Sulawesi Selatan 0,7

Pengkajian awal pada komite patient safety RSUD Kota Makassar didapatkan bahwa Insiden keselamatan pasien berdasarkan data dari sub komite patient safety pada tahun 2015-2017 didapatkan jumlah laporan KTD: 8 , KNC: 14, KTC 20 dan KPC: 19. Sedangkan data kejadian infeksi diperoleh dari sub komite PPI pada tahun 2015 - 2017 didapatkan laporan mengenai kejadian phlebitis sebanyak 996. Pengkajian manejemen kepala ruang pada bulan Oktober 2018 di RSUD Kota Makassar bahwa fungsi perencanaan kepala ruang terkait penerapan patient safety belum dilaksanakan secara maksimal. Pelaksanan fungsi pengorganisasian kepala ruang dalam menerapkan patient safety menyatakan bahwa belum ada pembagian khusus pada pasien tertentu dengan jenis penyakit tertentu. Pelaksanaan fungsi pengarahan kepala ruang dalam pelaksanaan asuhan keperawatan dalam penerapan patient safety belum berjalan maksimal. Pelaksanaan Fungsi pengendalian kepala ruangan terkait penerapan patient safety belum dilaksanakan sebagaimana mestinya

Profesi perawat merupakan salah satu profesi tersibuk dengan jam kerja yang tinggi dan tuntutan kerja yang tinggi pula. Profesi perawat merupakan profesi yang unik karena dalam prakteknya melibatkan emosi dan care terhadap pasien dan keluarga pasien. Jam kerja perawat sangat padat, dalam sehari perawat bekerja dalam shift kerja yaitu shift pagi, siang dan malam. Karena beban kerja yang tinggi menjadikan perawat memiliki resiko dalam melindungi keselamatan dirinya sendiri, pasien dan keluarga pasien.

Fenomena tersebut di atas menjadi dasar ditetapkannya rumusan masalah yaitu perencanaan, pengorganisasian, pengarahan dan pengarahan yang sesuai standar akan berpengaruh pada penerapan patient safety.

\section{METODE PENELITIAN}

Jenis Penelitian ini adalah penelitian kuantitatif dengan pendekatan (Cross Sectional), Populasi penelitian adalah perawat pelaksana di ruang rawat inap RSUD Kota Makassar yang berjumlah 198 orang dan jumlah sampel pada penelitian ini berjumlah 63 orang di pilih dengan menggunakan tehnik Purposive Sampling, pengambilan sampel berdasarkan pertimbangan tertentu yang telah dibuat peneliti, dan memenuhi kriteria inklusi: Perawat yang aktif bekerja di RSUD Kota Makassar, perawat yang telah bekerja minimal 1 tahun, serta yang bersedia menjadi responden. Variabel Independen pada penelitian ini adalah pelaksanaan fungsi manajemen keperawatan (perencanaan, pengorganisasian, pengarahan, dan pengendalian) kepala ruangan dan Variabel Dependen: penerapan patient safety oleh perawat pelaksana. Instrumen pada penelitian ini adalah berupa kuesioner yang digunakan untuk mendapatkan data pelaksanaan fungsi manajemen kepala ruangan dan penerapan patient safety oleh perawat di RSUD Kota Makassar. Teknik pengolahan data dengan editing, coding, tabulating data dan entry data hasil penelitaian ini dalam 2 kelompok yaitu analisis univariat, dan bivariate.

\section{HASIL PENELITIAN}

Hasil analisis univariat menunjukkan bahwa Persepsi fungsi manajemen keperawatan terbanyak 
kategori baik sebanyak 50,8\%, Persepsi fungsi manajemen keperawatan perencanaan terbanyak kategori baik sebanyak 79,3\%., Persepsi fungsi manajemen keperawatan pengorganisasian terbanyak kategori baik sebanyak 63,4\%, Persepsi fungsi manajemen keperawatan pengarahan terbanyak kategori baik sebanyak 74,6\%, Persepsi fungsi manajemen keperawatan pengendalian terbanyak kategori baik sebanyak $73 \%$, Penerapan patient safety terbanyak kategori baik sebanyak 68,2\%.

Hasil analisis bivariat menunjukkan bahwa ada hubungan pelaksanaan fungsi manajemen keperawatan dengan penerapan patient safety dengan nilai $\mathrm{p}$ value $=0,009$ ( $\mathrm{p}>0,05)$, Tidak ada hubungan pelaksanaan fungsi manajemen keperawatan perencanaan dengan penerapan patient safety dengan nilai $p$ value $=0,095(\mathrm{p}<0,05)$, ada hubungan pelaksanaan fungsi manajemen pengorganisasian kepala ruangan dengan penerapan patient safety oleh perawat dengan nilai $p$ value $=0,042(\mathrm{p}>0,05)$, tidak ada hubungan pelaksanaan fungsi manajemen pengarahan kepala ruangan dengan penerapan patient safety oleh perawat dengan nilai $p$ value $=0,530(\mathrm{p}<0,05)$, Ada hubungan pelaksanaan fungsi manajemen pengendalian kepala ruangan dengan penerapan patient safety oleh perawat dengan nilai $p$ value $=0,023(\mathrm{p}>$ $0,05)$.

\section{PEMBAHASAN}

Hasil penelitian menunjukkan bahwa pelaksanaan fungsi manajemen kepala ruangan baik mempunyai penerapan patient safety baik sebanyak $81,3 \%$ lebih besar dari penerapan patient safety kurang baik $18,7 \%$, sebaliknya penerapan fungsi manajemen kepala ruangan kurang mempunyai penerapan patient safety kurang 45,2\% lebih kecil dari penerapan patient safety baik 54,8\%. Hasil uji Spearman rho menunjukkan $\mathrm{p}$ value = $0,009$ ( $\mathrm{p}>0,05)$ maka dapat disimpulkan bahwa ada hubungan antara pelaksanaan fungsi manajemen kepala ruangan dengan penerapan patient safety oleh perawat di RSUD Kota Makassar.

Henri Fayol (dalam Siagian, 2007) berpendapat cara terbaik dalam menggerakkan anggota organisasi adalah dengan cara memberikan komando dan tanggung jawab pada pelaksanaan suatu kegiatan. Seorang kepala ruangan harus mampu menciptakan iklim kerja yang kondusif melalui kemampuan dalam memotivasi dan membimbing perawat pelaksana sehingga mereka mampu menerapkan patient safety dalam memberikan asuhan keperawatan dengan baik.

Hasil penelitian menunjukkan pelaksanaan fungsi manajemen perencanaan kepala ruangan baik mempunyai penerapan patient safety baik sebanyak $74 \%$ lebih besar dari penerapan patient safety kurang baik sebanyak $26 \%$, sebaliknya pelaksanaan fungsi manajemen perencanaan kepala ruangan kurang mempunyai penerapan patient safety kurang baik sebanyak 58,3\% lebih besar dari penerapan patient safety baik $46,2 \%$. Hasil uji Spearman rho menunjukkan $\mathrm{p}$ value $=0,095(\mathrm{p}>0,05)$ maka dapat disimpulkan tidak ada hubungan yang signifikan antara pelaksanaan fungsi manajemen pada perencanaan dengan penerapan patient safety oleh perawat di RSU Kota Makassar

Moekijat (2000) menyatakan bahwa fungsi perencanaan pelayanan dan asuhan keperawatan di ruang rawat inap yang dilaksanakan oleh kepala ruang sebagai pemikiran atau konsep-konsep tindakan tertulis seorang manajer. Sebelum melakukan perencanaan terlebih dahulu dianalisa dan dikaji sistem, strategi organisasi dan tujuan organisasi, sumbersumber organisasi, kemampuan yang ada, aktifitas spesifik dan prioritasnya.

Hasil penelitian ini sesuai dengan teori Terry, George R, (2009) bahwa perencanaan kepala ruang di ruang rawat inap meliputi perencanaan kebutuhan tenaga dan penugasan tenaga, 
pengembangan tenaga, kebutuhan logistik ruangan, program kendali mutu yang akan disusun untuk pencapaian tujuan jangka pendek, menengah dan panjang. Disamping itu kepala ruang merencanakan kegiatan di ruangan seperti pertemuan dengan staf pada permulaan dan akhir minggu. Tujuan pertemuan adalah untuk menilai atau mengevaluasi kegiatan perawat sudah sesuai dengan standar atau belum, sehingga dapat dilakukan perubahan-perubahan atau pengembangan dari kegiatan tersebut.

Hasil penelitian menunjukkan bahwa pelaksanaan fungsi manajemen keperawatan Pengorganisasian kepala ruangan baik mempunyai penerapan patient safety baik sebanyak 77,5\% lebih besar dari penerapan patient safety kurang sebanyak $22,5 \%$, sebaliknya pelaksanaan fungsi manajemen keperawatan Pengorganisasian kepala ruangan kurang mempunyai penerapan patient safety kurang sebanyak $47,8 \%$ lebih kecil dari penerapan patient safety baik sebanyak $52,2 \%$.

Hasil uji Spearman's rho menunjukkan $\mathrm{p}$ value $=0,042(\mathrm{p}<0,05)$. disimpulkan ada hubungan yang signifikan antara pelaksanaan fungsi manajemen keperawatan pengorganisasian kepala ruangan dengan penerapan patient safety oleh perawat di ruang rawat inap RSUD Kota Makassar.

\begin{tabular}{lrrr}
\multicolumn{2}{c}{ Penelitian ini } & sesuai dengan \\
pendapat Moekijat & $(2000)$ & yang \\
menyatakan & bahwa & prinsip-prinsip
\end{tabular}
pengorganisasian adalah pembagian kerja, kesatuan komando, rentang kendali, pendelegasian, koordinasi dan pengorganisasian bermanfaat untuk : penjabaran terinci semua pekerjaan yang harus dilakukan untuk mencapai tujuan, pembagian beban kerja sesuai dengan kemampuan perorangan/kelompok, dan mengatur mekanisme kerja antar masingmasing anggota kelompok untuk hubungan dan koordinasi.

Hasil penelitian ini sesuai dengan teori Terry, George R (2009), yang menyatakan bahwa setiap organisasi memiliki serangkaian tugas atau kegiatan yang harus diselesaikan untuk mencapai tujuan .Kegiatan perlu dikumpulkan sesuai dengan spesifikasi tertentu. Pengorganisasian kegiatan dilaksanakan untuk memudahkan pembagian tugas perawat sesuai dengan pengetahuan dan ketrampilan dimiliki serta sesuai dengan kebutuhan klien. Pengorganisasian tugas perawat ini disebut metode penugasan.

Hasil penelitian menunjukkan bahwa pelaksanaan fungsi manajemen keperawatan pengarahan kepala ruangan baik mempunyai penerapan pasien baik sebanyak 70,2\% lebih besar dari penerapan patient safety kurang sebanyak 29,8\%, sebaliknya pelaksanaan fungsi manajemen keperawatan pengarahan kepala ruangan kurang mempunyai penerapan patient safety kurang sebanyak 37,5\% lebih kecil dari penerapan patient safety baik sebanyak $62,5 \%$.

Hasil uji Spearman's rho menunjukkan $\mathrm{p}$ value $=0,530(p>0,05)$, dapat disimpulkan bahwa tidak ada hubungan yang signifikan antara pelaksanaan fungsi manajemen keperawatan pengorganisasian kepala ruangan dengan penerapan patient safety oleh perawat di ruang rawat inap RSUD Kota Makassar.

Hal ini dipengaruhi oleh adanya tingkat kesadaran masing-masing perawat yang berbeda, perawat yang mudah menerima masukan dan koreksi akan cenderung menerima dengan mudah perubahan yang ada, sehingga perawat yang akan lebih mudah untuk memberikan asuhan keperawatan yang lebih baik.

Hasil penelitian menunjukkan bahwa pelaksanaan fungsi manajemen keperawatan pengendalian kepala ruangan baik mempunyai penerapan patient safety baik sebanyak $76,1 \%$ lebih besar dari penerapan patient safety kurang sebanyak $23,9 \%$, sebaliknya pelaksanaan fungsi manajemen keperawatan pengendalian kurang mempunyai penerapan patient safety kurang sebanyak 52,9\% lebih besar dari penerapan patient safety baik sebanyak $47,1 \%$. 
Hasil uji Spearman's rho menunjukkan $p$ value $=0,023(\mathrm{p}<0,05)$ maka dapat disimpulkan bahwa ada hubungan yang signifikan antara pelaksanaan fungsi manajemen keperawatan pengendalian kepala ruangan dengan penerapan patient safety oleh perawat di RSUD Kota Makassar

Penelitian ini sesuai dengan pendapat Handoko, (2014) yang menyatakan bahwa pengendalian memungkinkan rencana yang telah dilaksanakan oleh sumber daya secara efektif dan efisien sesuai standar yang ditetapkan serta melakukan koreksi terhadap pelaksanaan kegiatan yang menyimpang. 14

Hasil penelitian ini sesuai dengan pendapat Swanburg,R.C, (2006) Untuk mencapai tujuan pelayanan keperawatan diperlukan supervisi keperawatan. Supervisi keperawatan adalah proses pemberian sumber- sumber yang dibutuhkan perawat untuk menyelesaikan tugas dalam rangka pencapaian tujuan. Adapun tujuan dari supervisi keperawatan adalah pemenuhan dan peningkatan kepuasan pelayanan pada klien dan keluarganya. Jadi supervisi difokuskan pada kebutuhan, ketrampilan, dan kemampuan perawat untuk melakukan tugasnya.

Pendapat peneliti dengan adanya fungsi pengawasan diharapkan pelaksanaan dari perencanaan yang telah ditetapkan dapat lebih terarah sesuai dengan standar yang telah ditetapkan. Pengawasan yang sistematis akan berdampak pelaksanaan asuhan keperawatan yang sesuai standar, sehingga pelayanan yang diberikan lebih efektif dan efesien. Oleh sebab itu fungsi pengendalian perlu dilaksanakan dan ditingkatkan pelaksanaannya agar meningkatkan penerapan patient safety untuk menjamin kualitas asuhan keperawatan di rumah sakit.

\section{KESIMPULAN} bahwa :

Hasil penelitian menunjukkan

1. ada hubungan yang signifikan antara pelaksanaan fungsi manajemen kepala ruangan dengan penerapan patient safety oleh perawat di RSUD Kota Makassar, sehingga dapat diartikan bahwa semakin baik pelaksanaan fungsi manajemen keperawatan kepala ruangan maka semakin baik pula penerapan patient safety oleh perawat di RSUD Kota Makassar.

2. Tidak ada hubungan yang signifikan persepsi antara pelaksanaan fungsi manajemen keperawatan perencanaan kepala ruangan dengan penerapan patient safety oleh perawat di RSUD Kota Makassar, maka dapat di artikan bahwa pelaksanaan fungsi manajemen perencanaan kepala ruangan belum dilakukan secara maksimal dan sebagai mana mestinya.

3. Ada hubungan yang signifikan antara pelaksanaan fungsi manajemen pengorganisasian kepala ruangan dengan penerapan patient safety oleh perawat di RSUD Kota Makassar, maka dapat diartikan bahwa pelaksanaan fungsi pengorganisasian perlu ditingkatkan dan dioptimalkan.

4. Tidak ada hubungan yang signifikan antara pelaksanaan fungsi manajemen pengarahan dengan penerapan patient safety oleh perawat di RSUD Kota Makassar, maka dapat diartikan bahwa pelaksanaan fungsi pengarahan kepala ruangan belum dilakukan sebagai mana mestinya.

5. Ada hubungan pelaksanaan fungsi manajemen pengendalian kepala ruangan dengan penerapan patient safety oleh perawat di RSUD Kota Makassar, sehingga dapat diartikan bahwa pelaksanaan fungsi pengendalian kepala ruangan telah dilakukan tetapi pelaksanaannya perlu ditingkatkan dan dan diefektifkan agar penerapan patient 
safety oleh perawat dapat memberikan pelayanan asuhan keperawatan yang berkualitas.

\section{Saran}

1. Kepala ruangan perlu meningkatkan pelaksanaan fungsi perencanaan dan pengarahan dalam upaya menerapkan patient safety sehingga akan terciptanya kualitas keselamatan pasien yang baik di lingkungan pelayanan RSUD Kota Makassar

2. Perawat diharapkan selalu menerapkan pentingnya program patient safety pada saat memberikan pelayanan asuhan keperawatan dengan berpedoman pada SOP yang ditetapkan di rumah sakit sehingga perawat dapat terhindar dari resiko terpapar penyakit atau menjadi vector penyebab penyakit bagi pasien, serta melindungi pasien dari cedera akibat kesalahan dalam pemberian asuhan keperawatan.

3. Keterbatasan Penelitian adalah penelitian ini bersifat observasi sehingga faktor dan variabel lain yang mempengaruhi penerapan patient safety perlu di kaji kembali lebih mendalam dengan metode yang lain.

\section{DAFTAR PUSTAKA}

Adventy R, Saragih M. (2018) Hubungan Fungsi Manajemen Kepala Ruangan dengan Penerapan Patient Safety di Rsud Dr. Pringadi Kota Medan

Alligood, M. R. (2014). Nursing Theorist and Their Work (8th ed.). Ohio: Elsevier.

Anwar. (2016). Hubungan fungsi Manajemen kepala ruangan dengan penerapan patient safety culture di rumah sakit umum Dr. Zainal Abidin Banda Aceh.

Anugrah, W (2013). Hubungan kepemimpinan efektif kepal ruangan dengan penerapan budaya keselamata pasien di instalasi rawat inap $R S$ Unhas

Burns, D. (2009). Clinical Leadership for General Practice Nurses. 3:
Leadership Mechanisms Practice Nursing, Vol 20, No 12

Dahlan, M. S. (2014). Statistik Untuk Kedokteran dan Kesehatan (6th ed.). Jakarta: Epidemologi Indonesia.

Datta, Biplab. (2015). Assessing the Efektiveness of Authentic Leadership. Vinod Gupta School of Management, Indian Institute of Tecnology, Kharagpur India

Depkes,RI. (2005). Standar Manajemen Pelayanan Keperawatan dan Kebidanan di Sarana Kesehatan (1st ed.). Jakarta: Direktorat Jendral Pelayanan Medik. Depkes RI.

Gitosudarmono, I. (2000). Manajemen Pemasaran. (BPFE, Ed.) (II). Yogyakarta.

Hamzah (2014). Hubungan fungsi controling kepala ruangan denga kepatuhan perawat pelaksana dalam penerapan patient safety di rumah sakit islam faisal Makassar

Hasniar. (2017). Penerapan Fungsi Manajemen dan Dampaknya terhadap Kinerja Kepala Ruangan di RSUD La Temmamala Kabupaten Sopeng, Thesis, Makassar: Fakultas Kesehatan Masyarakat Universitas Hasanuddin

Huber, D. (2014). Leadership and Nursing Care Management (5th ed.). Missouri: Elsevier.

Kementerian Kesehatan, RI. 2011. "PERATURAN MENTERI KESEHATAN REPUBLIK INDONESIA NOMOR 1691/MENKES/PER/VIII/2011

Kumajas, S. (2013). Hubungan Fungsi Manajemen Kepala Ruang Dengan Kinerja Perawat Dibadang Layanan Umum Daerah Rumah Sakit BLU RSUP Prof.Dr.R.D Kandou Manado.

Kurniadi, A. (2013). Manajemen keperawatan dan prospektifnya: Teori, konsep dan aplikasi (1st ed.). Jakarta: FKUI.

Marquis, B. L., \& Huston, C. J. (2010). Kepemimpinan dan manajemen keperawatan: Teori \& aplikasi (4th ed.). Jakarta: EGC. 
Notoatmodjo, S. (2012). Metodologi Penelitian Kesehatan. Jakarta: Rineka Cipta Nursalam. (2013). Konsep Penerapan Metode Penelitian Ilmu Keperawatan. Jakarta: Salemba Medika

Sopiydin, M Dahlan. (2014). Statistik Untuk kedokteran dan Kesehatan.(6th ed). Jakarta: Epidemiologi Indonesia

Nursalam. 2014. Manajemen Keperawatan: Aplikasi Dalam Praktek Keperawatan Profesional (4th ed). Jakarta: Salemba Medika

Pujilestari, A. (2013). Gambaran budaya keselamatan pasien oleh perawat dalam melaksanakan pelayanan di instalasi rawat inap rsup dr. Wahidin sudirohusodo, Thesis , Makassar: Universitas Hasanuddin

Rachmawaty, R. (2017). Ethical Issue in Action-Oriented Research in Indonesia, 686-93.

Sari, D. (2017). Pengaruh Fungsi Manajerial Kepala Ruang Terhadap Kinerja Individu Perawat Dalam Melaksanakan Asuhan Keperawatan Di Ruang Rawat Inap Rsud Aji Muhammad Parikesit Tenggarong Kalinantan Timur, Thesis, Makassar: Fakultas Kesehatan masyarakat Universitas Hasanuddin

Sastrohadiwiryo, S. (2002). Manajemen Tenaga Kerja Indonesia; Pendekatan
Administrasi dan Operasional. Jakarta: Bukit Aksara Setiadi. 2016. Manajemen Dan

Kepemimpinan Dalam Keperawatan. 1st ed. sleman, Yogyakarta: Indomedia Pustaka.

Siagian, (2009). Kiat Meningkatkan Produktivitas Kerja. Jakarta: Rineka Cipta

Simamora, R. (2012). Buku ajar: Manajemen keperawatan. Jakarta: EGC.

Sugiyono. (2014). Metode Penelitian kuantitatif, Kualitatif, dan $R \& D$. bandung: alfabeta.

Suni, A. (2013). Hubungan faktor determinan penerapan pasien safety dengan tanggung jawab perawat di ruang rawat inap rumah sakit $d r$. Wahidin Sudirohusodo Makassar.

Swansburg, R. C. (2000). Pengantar Kepemimpinan dan Manajemen Keperawatan.

Wardani, N (2013). Hubungan Kepemimpinan Efektif Kepala Ruangan dengan Penerapan Budaya Keselamatan Pasien di Instalasi Rawat Inap RS Unhas Makassar. Thesis , Makassar: Universitas Hasanuddin 